\title{
Resposta do milho verde à inoculação com Azospirillum brasilense e níveis de nitrogênio
}

\author{
Response of green corn to Azospirillum brasilense inoculation and $\mathrm{N}$ levels
}

\author{
Raul Matos Araújo ${ }^{\mathrm{I}}$ Ademir Sérgio Ferreira de Araújo ${ }^{\mathrm{I}^{*}}$ Luís Alfredo Pinheiro Leal Nunes $^{\mathrm{I}}$ \\ Marcia do Vale Barreto Figueiredo ${ }^{\text {II }}$
}

\section{- NOTA -}

RESUMO

O objetivo deste trabalho foi avaliar o efeito da inoculação com Azospirillum brasilense e adubação nitrogenada sobre a produtividade do milho verde. O estudo foi conduzido no município de Teresina, PI, em 2011 e 2012, $e$ os tratamentos foram dispostos em delineamento de blocos ao acaso sob arranjo fatorial de $5 \times 2$, sendo cinco doses de nitrogênio (N) $\left(0,50,100,150\right.$ e $\left.200 \mathrm{~kg} \mathrm{~N} \mathrm{ha}^{-1}\right)$ com e sem inoculação. No tratamento com inoculação, foi utilizado um produto formulado contendo A. brasilense, estirpes Abv5 e Abv6. Houve aumento significativo no número e na massa das espigas comerciais com a inoculação de A. brasilense em relação ao tratamento sem inoculação. A combinação de inoculação com A. brasilence e nitrogênio aumenta em mais de $30 \%$ a produção de espigas de milho verde.

Palavras-chave: fixação biológica de nitrogênio, Zea mays, Doses de $N$.

\section{ABSTRACT}

The aim of this study was to evaluate the effect of A. brasilense inoculation and nitrogen fertilization on green corn yield. The study was conducted out in Teresina, PI, in 2011 and 2012, and treatments were arranged in a randomized block design with five $\mathrm{N}$ rates $\left(0,50,100,150\right.$ and $\left.200 \mathrm{~kg} \mathrm{~N} \mathrm{ha}^{-1}\right)$ with and without inoculation. In the inoculated treatment it was used a product with A. brasilense, strains Abv5 and Abv6. There was a significant increase in both number and mass of commercial corn cobs with A. brasilense inoculation as compared with treatment without inoculation. The association of inoculation with A. brasilence and nitrogen increase more than $30 \%$ the corn cobs production.

Key words: biological nitrogen fixation, Zea mays. $N$ rates.

O milho verde tem importância alimentar através do seu consumo nas formas cozida, assada ou processada e, devido a sua aceitação e valor agregado, costuma atingir melhores preços de mercado do que o milho grão, tornando-se uma alternativa viável, principalmente para pequenos produtores (SANTOS et al., 2005). Entretanto, baixos níveis de produtividade têm sido obtidos em diversos locais e uma das principais causas é a baixa disponibilidade de nutrientes no solo, principalmente N (OLIVEIRA et al., 2009). Por outro lado, a cultura pode se beneficiar do processo de fixação biológica do nitrogênio (FBN) e, dessa forma, reduzir a dependência de fertilizantes nitrogenados.

A FBN é um processo de transformação do $\mathrm{N}_{2}$ na forma inorgânica combinada $\mathrm{NH}_{3}$, sendo realizado por microrganismos conhecidos por fixadores de $\mathrm{N}_{2}$ ou diazotróficos (NOVAKOWISKI et al., 2011). Dentre os diazotróficos, bactérias do gênero Azospirillum associam-se à rizosfera do milho e podem contribuir com a nutrição nitrogenada da cultura (FIGUEIREDO et al., 2009). Além disso,

\footnotetext{
ICurso de Engenharia Agronômica, Centro de Ciências Agrárias, Universidade Federal do Piauí (UFPI), 64049-550, Teresina, PI, Brasil. E-mail: asfaruaj@yahoo.com.br.*Autor para correspondência.

IIInstituto Agronômico de Pernambuco, Recife, PE, Brasil. 
essas bactérias podem promover o crescimento vegetal através da produção de fitoreguladores e sideróforos (NOVAKOWISKI et al., 2011) ou por aumentar a disponibilidade de fósforo (HUNGRIA et al., 2010). Contudo, os estudos mostram que a contribuição dessa bactéria para a produção de milho têm mostrado resultados contrastantes (HUNGRIA et al., 2010; BARTCHECHEN et al., 2010; GODOY et al., 2011). GODOY et al. (2011) utilizaram inoculante com Azospirillum brasilence e não encontraram respostas positivas da inoculação sobre a produtividade do milho. Por outro lado, HUNGRIA et al. (2010) avaliaram o uso de $\boldsymbol{A}$. brasiliense sobre o milho e encontraram um aumento em $30 \%$ na produtividade em relação ao controle sem inoculação. No caso do milho verde, não há trabalhos relacionados ao uso do Azospirillum e o efeito sobre a produtividade da cultura. Dessa forma, o objetivo do trabalho foi avaliar o efeito da inoculação com A. brasilense, associada à adubação nitrogenada, sobre a produtividade de milho verde.

Os estudos foram realizados no Centro de Ciências Agrárias da Universidade Federal do

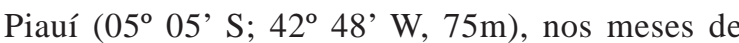
outubro a dezembro, em 2011 e 2012. O solo é classificado como Argissolo amarelo e o clima é do tipo Aw', tropical chuvoso (precipitação anual de $1000 \mathrm{~mm}$, distribuídos em janeiro a abril). As características químicas do solo $(0-20 \mathrm{~cm})$ antes da instalação dos experimentos, em 2011 e 2012, foram: pH 6,4 e 6,7; matéria orgânica 8,5 e 9,6g $\mathrm{kg}^{-1} ; \mathrm{P}, 12$ e $10 \mathrm{mg} \mathrm{dm}^{-3}$; K, 0,15 e 0,11 $\mathrm{cmol}_{\mathrm{c}} \mathrm{dm}^{-3}$; Ca, 1,4 e $1,6 \mathrm{cmol}_{c} \mathrm{dm}^{-3} ; \mathrm{Mg}, 0,6$ e $0,5 \mathrm{cmol}_{c} \mathrm{dm}^{-3}$ e CTC 3,8 e 4,1 $\mathrm{cmol}_{c} \mathrm{dm}^{-3}$, respectivamente. Em cada ano, o solo foi preparado por meio de aração e gradagem leve e adubado com P e K (80kg ha-1 de $\mathrm{P}_{2} \mathrm{O}_{5}$, na forma de superfosfato simples, e $60 \mathrm{~kg}$ $\mathrm{ha}^{-1}$ de $\mathrm{K}_{2} \mathrm{O}$, na forma de cloreto de potássio). Os tratamentos constaram de cinco níveis de $\mathrm{N}$, na forma de ureia $\left(0,50,100,150\right.$ e $\left.200 \mathrm{~kg} \mathrm{~N} \mathrm{ha}^{-1}\right)$ com e sem inoculação de Azospirillum brasilense. O N foi parcelado em três vezes (no plantio e em duas coberturas nos estádios V6 e V10). No tratamento com inoculação, foi utilizado inoculante líquido “Masterfix ${ }^{\circledR}$ Gramíneas”, contendo Azospirillum brasilense, estirpes Abv5 e Abv6, na concentração de $1,010^{9}$ células g ${ }^{-1}$.
As parcelas experimentais tiveram dimensões de 3,2x5,0m e constaram de quatro fileiras de 5,0m de comprimento, tendo como área útil as duas fileiras centrais. O espaçamento entre fileiras foi de $0,8 \mathrm{~m}$. Dentro da fileira, o espaçamento foi de $0,2 \mathrm{~m}$ entre covas, o que resultou em 25 covas por fileira, onde foram colocadas duas sementes por cova do milho híbrido (AG1051). A população final foi de 62500 plantas por hectare. As sementes foram inoculadas utilizando-se a dosagem de $500 \mathrm{~g}$ de inoculante para $50 \mathrm{~kg}$ de sementes. A semeadura foi realizada manualmente na primeira quinzena de outubro de cada ano. O desbaste foi feito aos dez dias após o plantio, deixando-se uma planta por cova. A irrigação por aspersão, com turno de rega diário, foi realizada utilizando uma lâmina d’água crescente com o desenvolvimento das plantas, atingindo a ordem de 8 mm diários entre os estádios V18 e R3. A colheita foi realizada aos 80 dias após o plantio, tomando como área útil as duas linhas centrais, eliminando $0,5 \mathrm{~m}$ nas extremidades. Na colheita, avaliou-se o número e a massa de espigas comerciais empalhadas (determinado em dez espigas tomadas ao acaso na parcela). Os dados foram analisados em delineamento experimental de blocos casualizados em arranjo fatorial 5x2, com quatro repetições, e submetidos à análise de variância e regressão, empregando-se o programa ASSISTAT (versão 7.4 beta) e as médias foram comparadas pelo teste de Tukey a $5 \%$.

Houve efeito significativo para inoculação, doses de $\mathrm{N}$ e para a interação inoculação $\mathrm{x}$ doses de $\mathrm{N}$ sobre as variáveis analisadas. Estes resultados indicam que houve comportamento diferenciado do milho verde para os componentes de produtividade pelo uso da inoculação e dos diferentes níveis de $\mathrm{N}$, isoladamente ou em conjunto. O número e a massa das espigas apresentaram valores superiores para o tratamento com inoculação da semente, quando comparado com o tratamento sem a bactéria. Independente da adubação com N, o tratamento com inoculação apresentou valores médios de 15,2 mil ha-1 e 6,2Mg ha ${ }^{-1}$, para o número e a massa de espigas, respectivamente (Tabela 1 ). No tratamento sem inoculação, os valores médios para número e a massa de espigas foram de 9,5 mil ha-1 e 3,6Mg ha $^{-1}$, respectivamente. Estes resultados indicam que houve efeito positivo da inoculação com $\boldsymbol{A}$. 
Tabela 1 - Número e massa de espigas comerciais de milho verde com (CI) e sem (SI) inoculação de Azospirilum brasilense e cultivado em solo sob diferentes níveis de N. Aos 80 dias após a emergência.

\begin{tabular}{|c|c|c|c|c|c|c|}
\hline \multirow[t]{2}{*}{ Tratamento } & \multicolumn{2}{|c|}{--------Número de espigas $\left(\mathrm{mil} \mathrm{ha}^{-1}\right.$ ) -------- } & \multirow[t]{2}{*}{ Média } & \multicolumn{2}{|c|}{---Massa de espigas $\left(\mathrm{t} \mathrm{ha}^{-1}\right)$----------- } & \multirow[t]{2}{*}{ Média } \\
\hline & $\mathrm{CI}$ & SI & & $\mathrm{CI}$ & SI & \\
\hline $0 \mathrm{~kg} \mathrm{ha}^{-1} \mathrm{~N}$ & $1,56 \mathrm{eA}$ & $1,24 \mathrm{eB}$ & 1,40 & $1,1 \mathrm{eA}$ & $0,7 \mathrm{eB}$ & 0,9 \\
\hline $50 \mathrm{~kg} \mathrm{ha}^{-1} \mathrm{~N}$ & $5,22 \mathrm{dA}$ & $4,29 \mathrm{~dB}$ & 4,75 & $2,7 \mathrm{dA}$ & $1,9 \mathrm{~dB}$ & 2,3 \\
\hline $100 \mathrm{~kg} \mathrm{ha}^{-1} \mathrm{~N}$ & 20,32 cA & $10,35 \mathrm{cB}$ & 15,33 & $8,1 \mathrm{cA}$ & $3,6 \mathrm{cB}$ & 5,8 \\
\hline $150 \mathrm{~kg} \mathrm{ha}^{-1} \mathrm{~N}$ & 31,35 aA & $21,34 \mathrm{~b}$ aB & 26,34 & $13,1 \mathrm{aA}$ & $6,1 \mathrm{aB}$ & 9,6 \\
\hline $200 \mathrm{~kg} \mathrm{ha}^{-1} \mathrm{~N}$ & 24,36 bA & $16,36 \mathrm{bB}$ & 20,36 & 9,4 bA & $5,2 \mathrm{bB}$ & 7,3 \\
\hline Média & 16,56 & 10,71 & - & 6,8 & 3,5 & - \\
\hline $0 \mathrm{~kg} \mathrm{ha}^{-1} \mathrm{~N}$ & $1,73 \mathrm{eA}$ & $1,42 \mathrm{eB}$ & 1,57 & $1,0 \mathrm{dA}$ & $0,6 \mathrm{~dB}$ & 0,8 \\
\hline $50 \mathrm{~kg} \mathrm{ha}^{-1} \mathrm{~N}$ & $4,92 \mathrm{dA}$ & $4,37 \mathrm{~dB}$ & 4,64 & $2,6 \mathrm{cA}$ & $1,7 \mathrm{cB}$ & 2,1 \\
\hline $100 \mathrm{~kg} \mathrm{ha}^{-1} \mathrm{~N}$ & $17,52 \mathrm{cA}$ & $7,65 \mathrm{cB}$ & 12,58 & 6,7 bA & $2,9 \mathrm{bB}$ & 4,8 \\
\hline $150 \mathrm{~kg} \mathrm{ha}^{-1} \mathrm{~N}$ & $27,15 \mathrm{aA}$ & $16,14 \mathrm{aB}$ & 21,64 & 10,3 aA & $5,2 \mathrm{aB}$ & 7,7 \\
\hline $200 \mathrm{~kg} \mathrm{ha}^{-1} \mathrm{~N}$ & 18,86 bA & $12,63 \mathrm{bB}$ & 15,74 & $7,1 \mathrm{bA}$ & $3,5 \mathrm{bB}$ & 5,3 \\
\hline Média & 14,03 & 8,43 & - & 5,5 & 3,8 & - \\
\hline
\end{tabular}

*Médias seguidas pela mesma letra minúscula, na linha, e maiúscula, na coluna, não diferem entre si pelo teste de Tukey a 5\%.

brasilense sobre a produtividade do milho verde e mostram incrementos significativos superiores a $30 \%$ na massa e número de espigas. Os valores são superiores aos obtidos em outros estudos com inoculação de $\boldsymbol{A}$. brasilense em milho, em que os aumentos variaram de 5 a 30\% (DIAZ-ZORITA \& FERNANDEZ CANIGIA, 2008; HUNGRIA et al., 2010; BARTCHECHEN et al., 2010).

Em relação aos níveis de $\mathrm{N}$ utilizados, os resultados mostram que, na média, houve um incremento significativo no número e na massa das espigas com o uso do nutriente (Tabela 1). Esse efeito positivo do $\mathrm{N}$ sobre o rendimento do milho já é bastante conhecido e reforça a importância do elemento para a cultura. Segundo BREDEMEIER \& MUNDSTOCK (2000), o $\mathrm{N}$ atua diretamente no desenvolvimento do milho, influenciando o rendimento da planta mais do que qualquer outro nutriente.

A análise conjunta entre a inoculação e os níveis de $\mathrm{N}$ mostrou, na média, que, com a inoculação, os valores máximos estimados, nos dois anos, foram de $22,5 \mathrm{mil} \mathrm{ha}^{-1}$ e 7,9 $\mathrm{Mg} \mathrm{ha}^{-1}$ de espigas com a aplicação de aproximadamente $160 \mathrm{~kg} \mathrm{ha}^{-1}$ de $\mathrm{N}$ (Figura 1). No tratamento sem inoculação, os valores máximos estimados, nos dois anos, foram de 12,2 mil ha ${ }^{-1}$ e $6,4 \mathrm{Mg} \mathrm{ha}^{-1}$ de espigas com a aplicação de aproximadamente $182 \mathrm{~kg} \mathrm{ha}^{-1} \mathrm{de} N$. Dessa forma, a inoculação com Azospirillum promoveu um aumento significativo na produtividade e uma redução na dose de $\mathrm{N}$ utilizada. Os resultados mostraram, ainda, que os maiores valores de número e massa de espigas foram obtidos com o uso da inoculação associado a altas doses de N. Isso sugere que a resposta da planta não ocorre apenas em razão do $\mathrm{N}_{2}$ fixado, mas, também pela maior eficiência de absorção de $\mathrm{N}$ mineral do solo (DOBBELAERE et al., 2003). Além disso, substâncias estimulantes do sistema radicular, tais como auxinas, podem ser liberadas pelo $\boldsymbol{A}$. brasilence e melhorar a eficiência do uso do $\mathrm{N}$ do solo (HUNGRIA et al., 2010; NOVAKOWISKI et al., 2011). Conclui-se, portanto, que a combinação de inoculação com $\boldsymbol{A}$. brasilence e $\mathrm{N}$ aumenta em mais de $30 \%$ o rendimento de espigas comerciais de milho verde, com redução de $15 \%$ na adubação nitrogenada

\section{AGRADECIMENTOS}

Ao Conselho Nacional de Desenvolvimento Científico e Tecnológico (CNPq) pela concessão das bolsas de Iniciação Científica a Raul Matos Araújo e Produtividade em Pesquisas à Ademir Sergio Ferreira de Araújo e Marcia do Vale Barreto Figueiredo. 


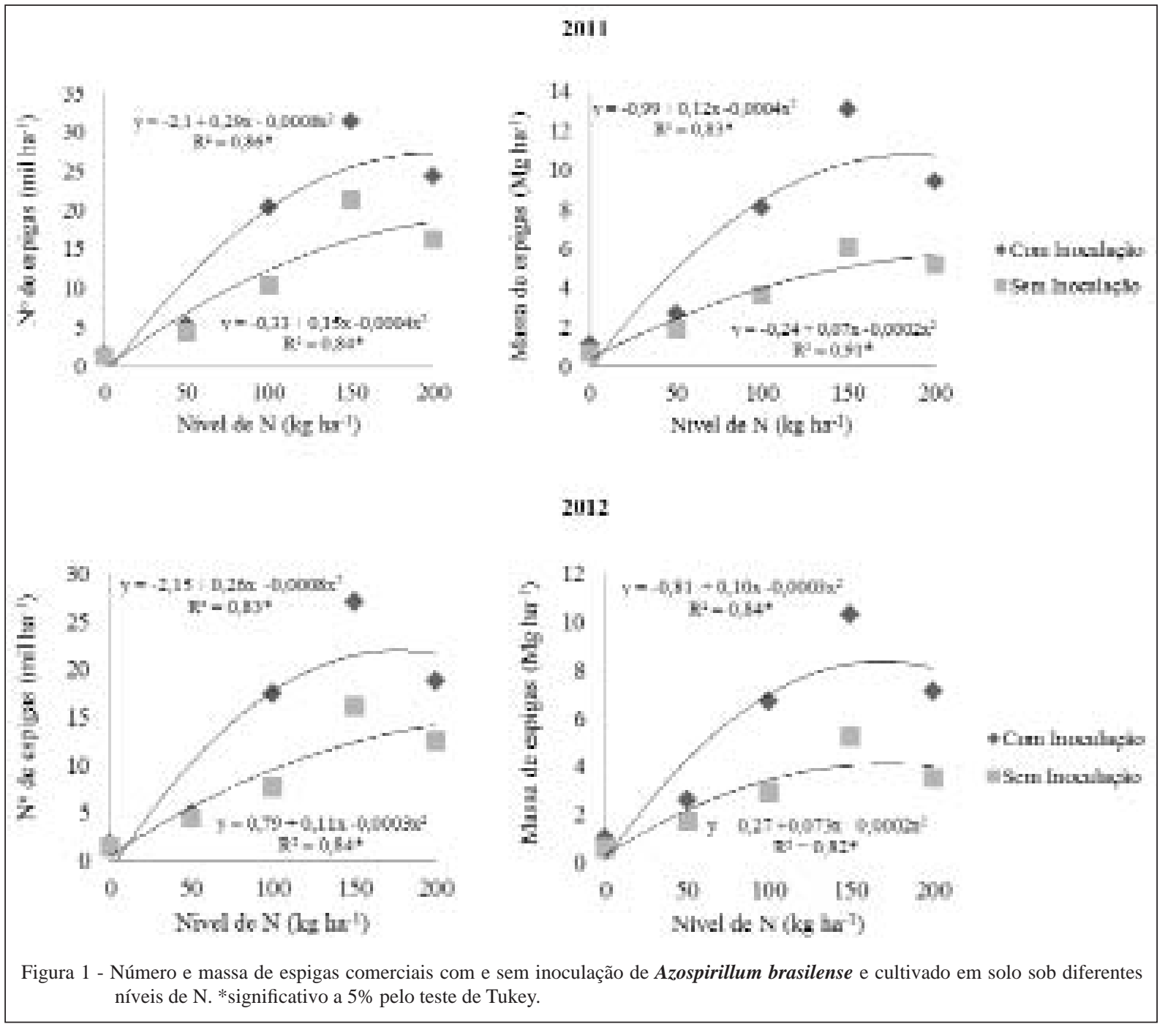

\section{REFERÊNCIAS}

BREDEMEIER, C.; MUNDSTOCK, CM. Regulação da absorção e assimilação do nitrogênio nas plantas. Ciência Rural, v.30, p.365-372, 2000. Disponível em: <http://dx.doi.org/10.1590/ S0103-84782000000200029>. Acesso em: 14 ago. 2013. doi: 10.1590/S0103-84782000000200029.

BARTCHECHEN, A. et al. Efeito da inoculação de Azospirillum brasilense na produtividade da cultura do milho (Zea mays l). Campo Digital, v.5, p.56-59, 2010. Disponivel em: <http:// revista.grupointegrado.br/revista/index.php/campodigital/article/ view/982>. Acesso em: 12 ago. 2013.

DÍAZ-ZORITA, M.; FERNANDEZ CANIGIA, M.V. Análisis de la producción de cereales inoculados con Azospirillum brasilense en la República Argentina. In: CASSÁN, F.D.; GARCIA DE SALAMONE, I. (Ed.). Azospirillum sp.: cell physiology, plant interactions and agronomic research in Argentina. Argentina: Asociación Argentina de Microbiologia, 2008. p.155-166.
DOBBELAERE, S. et al. Plant growth-promoting effects of diazotrophs in the rhizosphere. Critical Reviews in Plant Sciences, v.22, p.107-149, 2003. Disponível em: <http:// dx.doi.org/10.1080/713610853>. Acesso em 12 ago. 2013. doi: $10.1080 / 713610853$.

FIGUEIREDO, M.V.B. et al. Potential Impact of biological nitrogen fixation and organic fertilization on corn growth and yield in low external input systems. In: DANFORTH, A.T. (Ed.). Corn crop production growth, fertilization and yield. New York: Nova Science Publisher, 2009. p.227-255.

GODOY, J.C. et al. Produtividade de milho em resposta a doses de nitrogênio com e sem inoculação das sementes com Azospirillum brasilense. Campo Digital, v.6, p.26-30, 2011. Disponível em: <http://revista.grupointegrado.br/revista/index.php/campodigital/ article/view/980>. Acesso em: 12 ago. 2013.

HUNGRIA, M. et al. Inoculation with selected strains of Azospirillum brasilense and A. lipoferum improves yields of maize and wheat in Brazil. Plant and Soil, v.331, p.413-425, 2010. 
Disponível em: <http://link.springer.com/article/10.1007/s11104009-0262-0>. Acesso em 11 ago. 2013. doi: 10.1007/s11104-0090262-0.

OLIVEIRA, F.A. et al. Crescimento do milho adubado com nitrogênio e fósforo em um Latossolo Amarelo. Revista Brasileira de Ciências Agrárias, v.4, p.238-244, 2009. Disponível em: $<$ http://dx.doi.org/10.5039/agraria.v4i3a1>. Acesso em 11 ago. 2013. doi: 10.5039/agraria.v4i3a1.

SANTOS, I.C. et al. Comportamento de cultivares de milho produzidos organicamente e correlações entre características das espigas colhidas no estádio verde. Revista Brasileira de Milho e Sorgo, v.4, p.45-53, 2005. Disponível em: <http://rbms.cnpms. embrapa.br/index.php/ojs/article/view/126>. Acesso em 11 ago. 2013.

NOVAKOWISKI, J.H. et al. Efeito residual da adubação nitrogenada e inoculação de Azospirillum brasilense na cultura do milho. Semina: Ciências Agrárias, v.32, p.16871698, 2011. Disponível em: <http://dx.doi.org/10.5433/16790359.2011v32n4Sup1p1687>. Acesso em 11 ago. 2013. doi: 10.5433/1679-0359.2011v32n4Sup1p1687. 